\title{
Correction to: Taking Care of Our Own: Shoring Up Resilience and Preventing Suicide in Mental Health Professionals
}

Christine Moutier and Maggie Mortali

\section{Correction to:}

Chapter 7 in: M. B. Riba, M. Menon (eds.),

College Psychiatry, Psychiatry Update 1

https://doi.org/10.1007/978-3-030-69468-5_7

The references in the published version of the book had been cited incorrectly in chapter 7 and the same has been corrected in the revised version of the book.

The updated version of this chapter can be found at https://doi.org/10.1007/978-3-030-69468-5_7 